INDO GLOBAL JOURNAL OF

PHARMACEUTICAL SCIENCES

ISSN 2249- 1023

\title{
Emerging Detection Techniques in Breast Cancer using Quantum Dots
}

\author{
Asmita Arora, Kajal Kiran, Misthi Verma, Kushagra Bhardawaj, Vibha Rani * \\ Jaypee Institute of Information Technology, Sector 62, Noida, UP, India-201307
}

Address for Correspondance: Vibha Rani, vibha.rani@jiit.ac.in ; asmitaaarora@gmail.com ; kirankajal5@gmail.com ; misthi.verma@yahoo.in

\begin{abstract}
Keywords Breast Cancer; Quantum Dots; Western Blotting; Immunohistochemi stry.
\end{abstract}

\begin{abstract}
The occurrence of metastases is one of the main causes of death in many cancers and the main cause of death for breast cancer patients. Early cancer detection is one of the major aspects in cancer therapeutics. A lot of times, cancer is not detected in its early stages and is spotted when it's starts spreading to other organs. Common cancer detection techniques including western blotting, fluorescence in situ hybridization and immunohistochemistry have been exhaustively studied. However, there are two major drawbacks regarding these techniques. First, poor sensitivity for early detection of cancer. Second, these techniques fail to provide in-situ quantitative information with morphological features for multiple markers. With the present day technology, use of Quantum Dots has provided the potential to improve the early detection of cancer. Being extremely small in size $(2 \mathrm{~nm}-10 \mathrm{~nm})$, quantum dots have proven to challenge the traditional methods of cancer detection. These are presently used in detection of Breast cancer and Prostate cancer. Breast Cancer is still an alien concept to a large section of the society. It has been reported that every one woman in 8 holds a chance to develop Breast Cancer in her lifetime, while the figures are relatively smaller in men (1 in 1000). (C) 2016 iGlobal Research and Publishing Foundation. All rights reserved.
\end{abstract}

Conference Proceedings: International Conference on Advances in Plant and Microbial Biotechnology (PMB2017); JIIT, Noida: February 02-04, 2017

Indo Global Journal of Pharmaceutical Sciences( ISSN 22491023 ; CODEN- IGJPAI; NLM ID: 101610675) indexed and abstracted in EMBASE(Elsevier), SCIRUS(Elsevier),CABI, CAB Abstracts, Chemical Abstract Services(CAS), American Chemical Society(ACS), Index Copernicus, EBSCO, DOAJ, Google Scholar and many more. For further details, visit http://iglobaljournal.com 